\title{
Banco Mundial e as Recomendações Atuais para as Políticas Educacionais no Brasil
}

\author{
Jani Alves da Silva Moreira \\ Telma Adriana Pacifico Martineli \\ Renata Valério da Silva \\ Carolina de Moura Vasconcelos
}

Universidade Estadual de Maringá (UEM), Maringá/PR - Brasil

\section{Resumo}

Este texto tem como objetivo apresentar as recomendações do Banco Mundial (BM), no campo da influência nos ditames das políticas educacionais em vigência, a fim de evidenciar se essas recomendações têm sido propaladas em documentos atuais encomendados pelo governo brasileiro, delineados em leis, ações e programas da educação. Trata-se de um estudo exploratório sobre o tema, no qual, por meio de uma análise crítica e documental, analisa-se o alcance da influência dessa agência, mediante o contexto de intensificação do neoliberalismo, com vistas a inquirir como estão sendo assentadas essas recomendações na prática dos sistemas educacionais e como tem sido o delineamento das atuais reformas.

Palavras-chave: Banco Mundial. Políticas Educacionais. Reformas Educacionais.

\section{World Bank and Current Recommendations for Educational Policies in Brazil}

\section{Abstract}

This text aims to present the recommendations of the World Bank, in the field of influence on the dictates of educational policies in force, in order to highlight whether these recommendations have been promoted in current documents ordered by the Brazilian government, outlined in laws, actions and education programs. It is an exploratory study on the theme, in which, through a critical and documentary analysis, the scope of the influence of this agency is analyzed, in the context of intensification of neoliberalism, in order to inquire how these recommendations are being established in the practice of educational systems and how the current reforms have been outlined.

Keywords: World Bank. Educational Policies. Educational Reforms. 
Banco Mundial e as Recomendações Atuais para as Políticas Educacionais no Brasil

\section{Introdução}

Diversas pesquisas já foram produzidas para compreender a atuação do BM nas políticas para a educação brasileira. Há de se destacar que, a partir da década de 1990, ampliaram-se consideravelmente as produções $^{1}$ sobre a influência dos organismos internacionais na educação.

Afirmar que as recomendações do BM são implementadas na política educacional pode incorrer no risco de apenas considerar que as definições dessa política se estruturam de forma linear. Todavia, corroboramos o ponto de vista de Ball (2009, p. 305), o qual afirma que interpretar dessa forma é complexo, pois a política no contexto da prática "[...] é composta de muito mais do que a soma de uma gama de políticas e é tipicamente investida de valores locais e pessoais e, como tal, envolve a resolução de ou luta com, expectativa e requisitos contraditórios - acordos, ajustes secundários fazem-se necessários”. Logo, nas análises aqui mediadas, as recomendações do BM expressam-se em ideias que poderão ou não ser consentidas, legitimadas ou delineadas, mediante processos de enfrentamentos e disputas.

O texto em questão é resultado de um estudo exploratório, a partir de uma análise preliminar que aborda a origem e o papel do BM como agência multilateral do Sistema da Organização das Nações Unidas (ONU). Assim, o BM exerce influência no âmbito educacional, seja por meio das condicionalidades impostas nos contratos de empréstimos ou por consultorias e orientações técnicas (PRONKO, 2014). Destaca-se a atuação do Banco como formulador de proposições políticas, consultor e investidor de projetos educacionais, em seguida, discute-se sobre a presença de suas ideias nas reformas educativas atuais no Brasil.

A análise compreendeu a apreensão das recomendações do Banco, por base no exame crítico dos seguintes documentos selecionados: Banco internacional para a reconstrução e o desenvolvimento e corporação financeira internacional: estratégia de parceria de país para a república federativa do Brasil exercícios fiscais 2012 a 2015 (EPP) (BANCO MUNDIAL, 2011); Retomando o caminho para a inclusão, o crescimento e a sustentabilidade (RCICS) (BANCO MUNDIAL, 2016); Um Ajuste Justo: Análise e equidade do gasto público no Brasil (AJ) (BANCO MUNDIAL, 2017); Por um ajuste justo com crescimento compartilhado: uma agenda de reformas para o Brasil (AJCC) (BANCO MUNDIAL, 2018). A escolha desses documentos se justifica por apresentarem conteúdos que compõem uma agenda específica de recomendações para o Brasil, na qual a pauta é o crescimento econômico no contexto da crise do capital rentista, em que predominam as estratégias reformantes para o ajuste das contas públicas no País.

\section{O Banco Mundial e suas origens}

Criado em 1944, por meio da aliança política entre os países devastados pela Segunda Guerra Mundial (1939-1945), o Banco Mundial teve como objetivo inicial recuperar o setor econômico abalado. Soares (2009, p. 16), ao apresentar os mecanismos decisórios do banco, afirma que "[...] os estatutos do Banco Mundial estabeleceram que a influência nas decisões e votações é proporcional à participação no aporte de capital [...]". Os Estados Unidos da

1 Dentre as produções destacamos: Fonseca (2003); Leher (1998; 1999); Altmann (2002); Santos (2000); Silva (2003); Cardozo (2005); Pansardi (2009); Pereira (2010; 2018); Moreira (2012; 2015) e Pronko (2014). 
Banco Mundial e as Recomendações Atuais para as Políticas Educacionais no Brasil

América assumiram, desde o início da criação do grupo, o primeiro lugar nas votações e "hegemonia absoluta", pois, tradicionalmente, o cargo de presidência do Banco sempre é ocupado por um estadunidense.

Os empréstimos concedidos aos países signatários, por meio do Banco, podem ser agrupados em duas categorias, sendo elas investimento e ajustamento. O capital recebido é investido em tecnologias, programas de formação e treinamento, consultorias, reorganização de agências governamentais, projetos de infraestrutura, entre outros. O ajustamento fiscal é responsável pela recuperação de emergência em caso de desastres naturais ou atividades de reconstrução. Até meados de 1950, os empréstimos do BM concentraram-se nos países "capitalistas mais industrializados", ou seja, aqueles que economicamente não sofreram tanto impacto com o pós-guerra mundial. Esse cenário só sofreu mudanças em 1948, quando o grupo abriu sua carteira de empréstimos aos países periféricos (PEREIRA, 2010).

Durante setenta anos de sua existência, o BM teve por objetivo impulsionar o setor industrial dos países. Em 1968, iniciou-se a gestão de Robert McNamara (1968-1981) no BM, cujo objetivo era erradicar a pobreza e reestruturar a economia dos países periféricos. Após o período de cumprimento da missão primordial no provimento para a reconstrução dos países atingidos pelo pós-guerra, segundo Leher (1998), houve uma reorganização de prioridades, em que os empréstimos continuaram sendo concedidos, mas a cobrança sobre a economia dos países credores se intensificou. A administração de McNamara ficou marcada por uma ideologia do desenvolvimento, com orientações políticas e ações, nas quais a política de focalização, a equidade, a redistribuição de recursos e o impulso nos setores econômico e social foram destaques. Todavia, cabe frisar que:

[...] A ideologia do desenvolvimento tem como determinante a pujança econômica do EUA, sobretudo como ideologia política, expressando relações sociais que ultrapassam as fronteiras nacionais. Esta ideologia condensa relações de domínio da potência hegemônica sobre frações aliadas nos países industrializados avançados e, principalmente, sobre os agora denominados países em desenvolvimento (LEHER, 1998, p. 50).

As políticas do BM foram abalizadas pela influência do neoliberalismo, que constituiu em um alicerce ideológico para a atuação dessa agência. No caso do Brasil, que teve seu primeiro empréstimo aprovado em 1949, houve uma reorganização de prioridades. A educação passou a ser pauta na agenda do Banco, porém atrelada à reforma empresarial, uma vez que o campo empresarial ficou caracterizado como um setor que gera rendimentos, à luz do liberalismo econômico, sob a ação dos formuladores de políticas da "nova direita" (CASIMIRO, 2018; FREITAS, 2018).

No período atual, demarca-se que, na desestruturação da chamada democracia liberal, já não se assegura mais o livre mercado, tão pouco se garante a continuidade dos processos de acumulação individual da riqueza. $\mathrm{Na}$ análise de Freitas (2018, p. 22):

A 'nova direita' e seus aliados passam a implementar um conjunto de reformas que desestruturam a luta dos trabalhadores e colocam novos marcos de precarização da força de trabalho, ao mesmo tempo que recompõem as garantias do processo de acumulação. Para o neoliberalismo, as garantias deveriam ser incluídas nas constituições nacionais de forma a se tornar praticamente irrevogáveis, mesmo por caminhos que pudessem significar uma ruptura com as teses da democracia liberal. Afinal o que está em jogo é a própria 'liberdade pessoal e social' que precisa ser 
Banco Mundial e as Recomendações Atuais para as Políticas Educacionais no Brasil

defendida a qualquer custo para deter a ideia de uma economia planificada (contrária ao livre-mercado), de onde - dizem - advêm o 'esquerdismo' e o 'comunismo'. A ação do liberalismo econômico é, portanto, proativa, presciente de um risco futuro. Isso explica a sua narrativa belicosa permanente contra a 'social-democracia', o esquerdismo e o 'comunismo' - mesmo que não estejam no horizonte imediato.

$\mathrm{Na}$ nascente desse ideário, ainda no final dos anos 1980, com o Consenso de Washington $^{2}$, representantes de agências internacionais, dentre eles representantes do BM, juntamente com o governo dos EUA, redefiniram as exigências para a concessão de empréstimos e os cinco principais eixos acordados foram:

1. Equilíbrio orçamentário, sobretudo mediante a redução dos gastos públicos; 2. Abertura comercial, pela redução das tarifas de importação e eliminação das barreiras não tarifárias; 3. Liberação financeira, por meio da reformulação das normas que restringem o ingresso de capital estrangeiro; 4. Desregulamentação dos mercados domésticos, pela eliminação dos instrumentos de intervenção do Estado, como controle de preços, incentivos, etc.; 5. Privatização das empresas e dos serviços públicos (TOMMASSI; WARDE; HADDAD, 2003, p. 23).

Desde então, o BM exerce influência na formulação das políticas educacionais brasileiras e suas recomendações são geralmente consideradas ou justificadas por representantes e formuladores de políticas e, por meio dos projetos e contratos firmados, o País se enquadra nas exigências dos contratos e firma políticas de ajustes estruturais. Vale destacar que foi a partir da década de 1990, especificamente no ano de 1995, que o BM publicou o primeiro documento para o sistema educacional com orientações e recomendações para a América Latina e Caribe, intitulado Prioridades y Estrategias para la Educacion (1995), que evidenciou recomendações mediante seis eixos, sendo: a centralidade na educação básica, a focalização no ensino fundamental, parceria, equidade, descentralização e autonomia (BANCO MUNDIAL, 1995).

Esse documento chamou a atenção por apresentar um pacote de medidas neoliberais que nortearam as discussões e debates em torno da legislação brasileira da época, com foco no ensino primário ${ }^{3}$. Nesse documento, o discurso defendia o ponto de vista de que o indivíduo necessitava do básico para o ingresso no mercado de trabalho. Na visão do BM, qualquer formação adicional não deve ser responsabilidade do Estado, mas, sim, da iniciativa privada. Pode-se evidenciar, desde esse período, a presença de recomendações que visavam a participação da sociedade civil, foco na eficiência e nos resultados, objetivando a privatização da educação pública.

2 Para aprofundamento, indicamos Silva (2005, p. 256).

3 A expressão "ensino primário" utilizada nos documentos do BM refere-se aos anos inicias de escolarização do Ensino Fundamental e à segunda etapa do Ensino Fundamental. A Clasificación Internacional Normalizada de la Educación (CINE) (UNESCO, 2011, p. 32) conceitua como Educação Primária a fase de escolarização que: "En general, la edad habitual o legal de ingreso no es inferior a los 5 años de edad ni superior a los 7 años de edad. Este nivel suele tener una duración de seis años, aunque esta puede fluctuar entre cuatro y siete años. A su vez, la edad de salida de la educación primaria está situada típicamente en el rango de 10 a 12 años (véanse los párrafos 132 al 134). Una vez concluidos los programas de educación primaria, el niño continúa su educación en el nivel CINE 2 (educación secundaria baja)". 
Banco Mundial e as Recomendações Atuais para as Políticas Educacionais no Brasil

\section{O Banco Mundial, a Nova Direita e as reformas educacionais}

Ao compreender a atuação do BM nas políticas educacionais, Borges (2003) assinala, em linhas gerais, que "[...] a agenda de políticas do Banco Mundial deslocou-se das reformas macroeconômicas strictu sensu para as reformas do Estado e da administração pública objetivando promover a 'boa governança' [...]" (BORGES, 2003, p. 125). O autor destaca ainda que houve políticas de ajustes estruturais que influenciaram as políticas educacionais, de modo que as reformas educacionais tiveram destaque no ajuste econômico, restrições no orçamento, relação mais intensa com o setor privado e desburocratização do Estado.

Em contrapartida, há quem defenda que os investimentos na educação são suficientes e que as reformas não obtiveram sucesso devido à falta de preparo do sistema educacional da América Latina. Gajardo (1999) enfatiza que há investimentos por parte dos governos, porém os recursos são mal gerenciados e, portanto, afirma que os pacotes de medidas elaborados pelo BM são a saída para os desafios enfrentados pelo sistema educacional. $\mathrm{Na}$ visão da autora, as reformas educacionais foram descontínuas, descentralizadas e focalizadas, objetivando atender às exigências dos organismos internacionais na formulação de saídas paliativas e incoerentes, muitas vezes, com a própria realidade dos países. Como resultado desse processo, pode-se verificar o consenso aos ditames do mercado de trabalho, desconsiderando a função social da educação e transformando-a em um instrumento para alívio da pobreza.

Com o golpe parlamentar, jurídico e midiático ${ }^{4}$, nomeadamente após o impeachment de Dilma Rousseff ${ }^{5}$ (2011 a 2016), assumiu então seu vice Michel Temer (2016-2018), iniciando a implantação de uma reforma na educação pública. O contexto representa o enfrentamento de novas reformas pautadas na intensificação do ideário ultraneoliberal, no qual a nova direita, com sua face autoritária, representa um "lado reacionário e golpista, corroendo a lógica da democracia liberal por dentro" (FREITAS, 2018, p. 25) e nos remete a questionar se essas reformas são realmente novas ou velhas roupagens ancoradas em recomendações econômicas, pois:

[...] compreende-se que estes defensores do liberalismo econômico abram mão da democracia para garantir o que conceituam como 'liberdade', legitimando golpes militares e/ou jurídico-parlamentares-institucionais. Compreende-se, também, o motivo da violência política estar colocada na ordem do dia como forma de barrar as teses de qualquer movimento que envolva minimamente algum tipo de planejamento econômico com algum papel relevante do Estado. O Estado é visto como algo que atrapalha a liberdade individual de competir ao olhar para o bem-estar do coletivo (FREITAS, 2018, p. 26).

Inserido nesse contexto e em consonância com esses ideais, destacou-se no período o programa governamental divulgado no documento Uma Ponte para o Futuro (2015), produzido pelo Partido do Movimento Democrático Brasileiro $(\mathrm{PMDB})^{6}$, que caracterizou medidas austeras do neoliberalismo no período. Representou o início de uma face

\footnotetext{
4 Utilizamos o termo amparado nas análises de Lucena, Previtali e Lucena (2017) e Jinkings, Doria e Cleto (2016) e Freitas (2018).

5 O processo para o impedimento da continuidade de mandato de Dilma Rousseff como Presidente do Brasil teve o início em 02 de dezembro de 2015 e encerrou-se em 31 de agosto de 2016.

6 Em dezembro de 2017, o partido voltou a se chamar Movimento Democrático Brasileiro (MDB).
} 
Banco Mundial e as Recomendações Atuais para as Políticas Educacionais no Brasil

devastadora das políticas econômicas na fase atual da crise do capital, uma violação constitucional alarmante.

De acordo com Avritzer (2018), o governo de Temer estruturou uma agenda própria que se aproximou das recomendações do Banco Mundial, o que demonstra que o governo tem tomado medidas que, cada vez mais, equipara a educação aos modelos de gestão empresarial. Medidas que foram tomadas durante o governo Temer, como a Medida Provisória (MP) n 746/2016, que reduz o ensino médio a um ensino técnico com a busca de eficiência ou a redução de investimentos públicos, como a Proposta de Emenda Constitucional (PEC) $n^{\circ}$ 241/2016 ou PEC $n^{\circ} 55$, demonstram uma aproximação das medidas educacionais brasileiras às recomendações do BM.

As recomendações analisadas nos documentos do BM referem-se a uma educação com viés mercadológico, baseada em rendimentos e retorno do capital. Nesse sentido, com a realidade das reformas educacionais, verifica-se uma adequação às demandas do BM e presença das suas recomendações nas reformas educacionais em andamento, dentre elas, a reforma do Ensino Médio, as mudanças curriculares por meio da Base Nacional Comum Curricular e o contingenciamento dos gastos para a saúde educação a ser efetuado nos próximos 20 anos.

A proposta do governo de Michel Temer (2016-2018) baseou-se na reforma do Estado propondo um Estado ativo, moderno e funcional:

As modernas economias de mercado precisam de um Estado ativo e também moderno. Quem nos diz isto não é apenas a teoria econômica, mas a experiência histórica dos países bem-sucedidos. Só o Estado pode criar e manter em funcionamento as instituições do Estado de Direito e da economia de mercado, e só ele também pode suprir os bens e serviços cujos benefícios sociais superam os benefícios privados. Portanto, as discussões sobre o tamanho e o escopo do Estado quase sempre se movem no vazio, porque a questão central é que o Estado deve ser funcional, qualquer que seja o seu tamanho. Para ser funcional ele deve distribuir os incentivos corretos para a iniciativa privada e administrar de modo racional e equilibrado os conflitos distributivos que proliferam no interior de qualquer sociedade. Ele faz ambas as coisas através dos tributos, dos gastos públicos e das regras que emite. Essas são tarefas da política e, por isso, é justo dizer que o crescimento econômico duradouro e sustentável é uma escolha da política, do sistema político e dos cidadãos como agentes políticos (FUNDAÇÃO ULYSSES GUIMARÃES; PMDB, 2015, p. 4, grifos nossos).

Nas entrelinhas das propostas contidas no documento, é possível evidenciar que o programa do governo de Temer (2016-2018) teve como base os modelos de economia dos países centrais, induzindo a privatização e menos intervenção do Estado. As mudanças nas ações do Estado perpassam o nexo da regulação e os limites para o mercado, enquanto que, ao mesmo tempo, o Estado "cria condições nas quais o mercado pode florescer e expandir"; essa flexibilização das ações do Estado é denominada de mudanças de governo para governança ou também chamado de metagovernança (BALL, 2014, p. 47 e 64). Diante disso, o documento também descreve um cenário de crise, no qual explicita que, durante os anos anteriores, o governo federal cometeu "excessos", na ampliação de programas ou novos programas e investimentos dos tributos. Afirma ainda que a situação atual poderia estar "menos crítica", como prescreve: 
No entanto, a parte mais importante dos desequilíbrios é de natureza estrutural e está relacionada à forma como funciona o Estado brasileiro. Ainda que mudássemos completamente o modo de governar o dia a dia, com comedimento e responsabilidade, mesmo assim o problema fiscal persistiria. Para enfrentá-lo teremos que mudar leis e até mesmo normas constitucionais, sem o que a crise fiscal voltará sempre, e cada vez mais intratável, até chegarmos finalmente a uma espécie de colapso (FUNDAÇÃO ULYSSES GUIMARÃES; PMDB, 2015, p. 5).

O plano governamental do partido teve como intuito "preparar o terreno" para o que nos aguardava. Referiu-se às reformas descontínuas, ao atendimento às exigências internacionais, à minimização do papel do Estado nos serviços públicos, incentivo à privatização e a disseminação de um panorama de medidas descentralizadoras que se concretizaram no decorrer dessa gestão, conforme evidenciam as autoras:

Ao propor a desvinculação de recursos para a educação, esse programa retira a garantia de igualdade de condições para todos, além disso, destaca o papel do Estado para estabelecer parcerias com o setor privado, reflete uma proposta de educação dualista, em que as pessoas da classe trabalhadora terão uma educação voltada para o mercado de trabalho, reduzindo a possibilidade de conhecimento e emancipação humana. Assim, opta por favorecer a iniciativa privada, inclusive destinando recursos públicos para ela [...] (RUIZ; BUFALO, 2017, p. 55).

No período de gestão do governo Temer, as propostas para a educação tiveram características focalizadas, descontínuas, contraditórias e perversas no sentido de agravar as medidas ultraneoliberais na educação. A reforma do Ensino Médio, subsidiada com empréstimos advindos do $\mathrm{BM}$, caracterizou o início dessas mudanças na configuração do sistema educacional.

É possível identificar que as recomendações do BM para o Brasil se intensificaram no campo da economia, com vistas ao ajuste dos gastos públicos, a partir do governo Temer. $\mathrm{Na}$ área da educação fica notória a intensificação do viés economicista, por meio de políticas austeras de ajuste, assentadas na reformulação do papel do Estado e sua governança corporativa ${ }^{7}$.

A confirmação disso está nos documentos específicos que foram lançados no período analisado, dentre eles destaca-se o documento intitulado "Banco internacional para a reconstrução e o desenvolvimento e corporação financeira internacional: estratégia de parceria de país para a república federativa do Brasil exercícios fiscais 2012 a 2015" Relatório No 63731-BR - EPP (BANCO MUNDIAL, 2011). Esse documento refere-se a um estudo que lança recomendações políticas com base na avaliação da cooperação financeira internacional. Por conseguinte, traça orientações para 2012 a 2015, cujo objetivo é abranger cinco aspectos: Objetivo 1: Aumentar a eficiência dos investimentos públicos e privados;

\footnotetext{
Sobre a aplicabilidade da governança corporativa nos países signatários do BM, em especial, os países da América Latina, cabe esclarecer que a Corporação Financeira Internacional (IFC), que integra o Grupo do BM, é ativa no Fórum Global de Governança Corporativa (GCGF). O GCGF "é um fundo fiduciário de vários doadores da Corporação Financeira Internacional (IFC), que integra os Serviços de Consultoria da instituição. Fundado em 1999 pelo Banco Mundial e pela Organização para a Cooperação e Desenvolvimento Econômico (OCDE), o Fórum promove o setor privado como motor do desenvolvimento econômico, reduz a vulnerabilidade de economias em desenvolvimento e em transições em crises financeiras e incentiva que as empresas invistam para produzir com mais eficiência e responsabilidade social. $O$ Fórum patrocina iniciativas locais e regionais que debatam os pontos fracos da governança corporativa" (BANCO MUNDIAL, 2009, p. 04, grifos nossos).
} 
Objetivo 2: Melhorar a prestação de serviços públicos para famílias de baixa renda; Objetivo 3: Promover o desenvolvimento econômico regional; Objetivo 4: Melhorar a gestão sustentável de recursos naturais e a resiliência ao clima. No relatório é possível encontrar recomendações políticas para a educação centradas na focalização da pobreza, no qual o BM prevê uma maior qualidade da educação, especialmente para pobres (BANCO MUNDIAL, 2011, p. 27).

Priorizou-se, para este texto, a análise do Objetivo 5 proposto pelo BM, que define o foco no aumento da eficiência dos investimentos públicos e privados. No que tange a esse objetivo, o Banco propunha apoiar o Brasil em cinco eixos de ações. O primeiro eixo referese ao investimento dos recursos públicos e recursos de empréstimos do BM no setor privado, sob a justificativa de que esse mecanismo diminui custos e expande o ensino superior no País.

O segundo eixo de ação refere-se às políticas que visam aplicar a política por desempenho, a meritocracia, denominado pelo BM de Desempenho de professores e desenvolvimento (ECD), no qual a responsabilização da qualidade da educação é responsabilidade da gestão escolar, que deve agir com eficácia e eficiência nas escolas (BANCO MUNDIAL, 2011, p. 25).

De acordo com as análises, a palavra eficiência é muito presente nos discursos do BM e tem como proposta enunciativa que a escola adote as nomenclaturas empresariais. Na visão do BM, a educação precisa ser eficiente, nas entrelinhas, é uma educação na qual os profissionais que nela atuam suportam todas as dificuldades presentes e enfrentadas nessa carreira profissional: baixo salário, desvalorização, salas superlotadas, pouco domínio de turma, em casos de salas com muitos alunos, a violência escolar. Soma-se a isso, como recompensa aos professores por enfrentar tantos desafios, as bonificações por mérito:

Os programas de remuneração variável para professores são definidos [...] de acordo com o conceito do Banco Mundial: pagamentos que deixam a base salarial intacta, mas criam incentivos na margem, com a oferta de um bônus anual (ou mensal) baseado em algum tipo de medida do desempenho do professor (DE BONIS, 2015, p. 73).

Atribui-se a aos professores a responsabilidade pela melhoria da qualidade da educação. Em função disso, predomina um forte apelo às políticas de valorização de professores, por meio de incentivos financeiros, com base em resultados e mérito. Essas políticas acabam por incitar a competitividade, concorrência e o individualismo entre os professores. O reconhecimento do trabalho de professores fica condicionado aos resultados de avaliações, visto que os professores que se "beneficiam" dessa bonificação são aqueles cujos alunos se destacam em exames nacionais.

A avaliação aliada à política de desempenho e desenvolvimento (ECD) é o terceiro eixo de ação, no qual se recomenda "Apoiar os grandes municípios selecionados na elaboração, implementação e avaliação de impactos de programas de Desempenho de professores e desenvolvimento (ECD) piloto direcionados às famílias de baixa renda, focando nas abordagens inovadoras com grandes efeitos potenciais de demonstração" (BANCO MUNDIAL, 2011, p. 25).

O quarto eixo propõe políticas que envolvam parcerias com governos locais/municipais e estaduais para o alcance da qualidade da educação, no qual o maior problema é apontado 
Banco Mundial e as Recomendações Atuais para as Políticas Educacionais no Brasil

pelo BM como sendo a melhora da qualidade dos professores, a qualidade do ensino médio e as repetições e distorções idade-ano (BANCO MUNDIAL, 2011).

Como quinto eixo de ação, o BM enfatiza a necessidade de trabalhos e pesquisas analíticas para a melhoria da eficiência do ensino profissional e técnico no Brasil. Ressalta-se ainda que o Relatório em análise denota de forma recorrente recomendações para o Desempenho de professores e desenvolvimento da primeira infância (ECD), no qual se visa "[...] avaliar programas inovadores de pagamento por desempenho que vinculam os bônus dos professores aos resultados de desempenho dos alunos, bem como a prestação de serviços de creches públicas no município" (BANCO MUNDIAL, 2011, p. 25). Mediante as recomendações do banco, "[...] o programa de ECD mostra impactos significativos na participação da força de trabalho das mães; a avaliação também medirá os efeitos do programa sobre o desenvolvimento cognitivo das crianças" (BANCO MUNDIAL, 2011, p. 25).

Outro documento que apresenta o foco no crescimento econômico e no ajuste dos gastos públicos no Brasil é o Relatório $\mathrm{N}^{\circ}$ 101.431, no qual se encontra um diagnóstico elaborado por uma equipe central do BM que reforça análises nas Práticas Globais $(P G)^{8} \mathrm{e}$ na Corporação Financeira Internacional (IFC). O documento intitula-se Retomando o caminho para a inclusão, o crescimento e a sustentabilidade (RCICS) (BANCO MUNDIAL, 2016) e segue a mesma linha do documento anterior, todavia, com o foco no quadro econômico crítico do País, no qual o BM desenvolve uma descrição para a proposição de direcionamentos focados na "economia de mercado dinâmica e competitiva", mas inclusiva (BANCO MUNDIAL, 2016, p. XXI), que deve se enquadrar nas seguintes ações elencadas: aumentar a eficiência com a diminuição de gastos com a previdência; focalização na pobreza e apoio ao mercado com diminuição de investimento em pesquisas científicas:

\section{[...] alguns dos maiores itens de gastos públicos na esfera social beneficiam as pessoas em melhor situação econômica - as aposentadorias do setor público são um exemplo óbvio (BANCO MUNDIAL, 2016, p. iv);}

Com uma reforma na previdência social, redução dos desperdícios, revogação de subsídios ineficientes e realocação de recursos para serviços que beneficiem principalmente os $40 \%$ da população mais pobre [...] (BANCO MUNDIAL, 2016, p. vi);

[...] as políticas públicas precisam ir além do financiamento público das pesquisas científicas e de verbas públicas para apoio à inovação em nível individual (BANCO MUNDIAL, 2016, p. xxi).

No documento Um Ajuste Justo: Análise e equidade do gasto público no Brasil (AJ) (BANCO MUNDIAL, 2017), encomendado pelo governo federal, postula-se que o documento tem "[...] o objetivo de realizar uma análise aprofundada dos gastos do governo, identificar alternativas para reduzir o déficit fiscal a um nível sustentável [...]" (BANCO MUNDIAL, 2017, p. 1). Em seu resumo executivo, o documento declara que o "[...] Governo Brasileiro gasta mais do que pode e, além disso, gasta mal. Esta é a principal conclusão deste estudo, que

8 As Práticas Globais (PG) do BM são conhecidas como as áreas de ação do Banco, onde ocorrerão empréstimos ou consultorias técnicas. São 14 áreas, a saber: 1. Agricultura, 2. Governança, 3. Ambiente e Recursos Naturais, 4. Macroeconomia e Gestão Fiscal, 5. Água, 6. Pobreza, 7. Comércio e Competitividade, 8. Proteção Social e Trabalho, 9. Educação, 10. Saúde, Nutrição e População, 11. Energia e Extrativos, 12. Social, Urbano, Rural e Resiliência, 13. Finanças e Mercados; 14. Transporte e ICT (BANCO MUNDIAL, 2019). 
Banco Mundial e as Recomendações Atuais para as Políticas Educacionais no Brasil

analisa as raízes dos problemas fiscais recorrentes do Brasil e apresenta opções para sua solução" (BANCO MUNDIAL, 2017, p. 1).

O documento propõe soluções para a "instabilidade econômica" do País, argumentando que, após a mudança de governo, o setor econômico enfrenta uma crise, cuja solução apresentada pelo BM se resume no desenvolvimento de mecanismos de privatização dos serviços públicos, como a educação. São apresentados os "níveis de despesas do setor de educação" e conclui-se que o Brasil gasta mais do que a média dos países da Organização para a Cooperação e Desenvolvimento Económico (OCDE) em educação. "Em 2014 [...] as despesas com educação chegaram a $6 \%$ do PIB" (BANCO MUNDIAL, 2017, p. 122). Além disso, segundo o mesmo relatório, "[...] Os resultados de educação melhoraram no Brasil, mas permanecem baixos ao se considerar o drástico aumento dos gastos" (BANCO MUNDIAL, 2017, p. 124).

Vale contra-argumentar que, se o BM afirma que, em 2014, as despesas com educação chegaram a $6 \%$ do PIB, o que nos aguarda diante da regra do Novo Reajuste Fiscal é uma avalanche de retrocessos. Uma projeção dos gastos públicos desenvolvida no documento Austeridade e Retrocesso: Finanças Públicas e Política Fiscal no Brasil (BRASIL DEBATE, 2018) demonstra que o gasto primário total do Governo Federal passaria de 19,6\% do PIB, em 2015, para $15,8 \%$, em 2026, e para $12 \%$, em 2036. Portanto, diante da nova regra, a educação é brutalmente desvalorizada. Rossi e Dweck (2016, p. 1) afirmam que:

\section{[...] com o congelamento das despesas com saúde e educação, estas passarão de $4 \%$ do PIB em 2015 para $2,7 \%$ do PIB em 20 anos, quando a população brasileira será $10 \%$ maior. Enquanto que os outros gastos federais (excluindo previdência e juros) que eram 7\% do PIB em 2015 serão de 0,6\% do PIB em 2036, o que não parece tecnicamente, tampouco politicamente, factível.}

Outra questão avaliada por Bassi (NASCENTES; SALINET, 2017) diz respeito à situação econômica, pois, caso a economia cresça, o valor mínimo será corrigido apenas conforme a inflação. Todavia, na prática, o investimento em educação será menor, no que se refere à porcentagem do PIB, o que já se avista como consequência ao não cumprimento do Plano Nacional de Educação de 2014.

Outra questão em destaque no documento do BM é a responsabilização dos professores pelos baixos níveis na qualidade da educação que são apresentados pelo Brasil. O documento alega que "[...] a baixa qualidade dos professores é o principal fator restringindo a qualidade da educação" (BANCO MUNDIAL, 2017, p. 127). O discurso retrata ainda a profissão do professor como "desprestigiada", os cursos de licenciatura "fracos e a formação é de baixa qualidade", refletindo assim na sua atuação em salas de aula, logo, prejudicando os alunos que apresentam baixos índices no Programa Internacional de Avaliação de Alunos (Pisa).

Diante da problemática registrada no documento do BM, é possível também evidenciar recomendações que conduzem para a contratação de professores terceirizados ou por meio de contratos precários em processo de desprofissionalização, por notório saber ou sem formação específica no magistério. Em estudo recente, Moreira (2018) chama a atenção para a presença dessa recomendação no documento em tela:

[...] Para colocar em prática a EC $n^{\circ} 95$, o documento sugere algumas medidas como a redução salarial, reforma do sistema previdenciário (p. 70), recompensas por melhor 
Banco Mundial e as Recomendações Atuais para as Políticas Educacionais no Brasil

desempenho do servidor público, atrair profissionais do setor privado, terceirização de serviços e sistema rigoroso de avaliação de desempenho e rever os planos de carreira. O Relatório expressa que os planos de carreira 'deveriam ser baseados na aquisição de competências e no desempenho'. Segundo o documento há um número excessivo de professores e para diminuir os gastos deve-se aumentar o número de alunos por professor (p. 129). Propõem o aumento de eficiência por meio de bônus e avaliação por desempenho (p. 131). Destaca ainda que o Ensino Superior Gratuito pode estar perpetuando a desigualdade no país (p. 136) e recomendam que deve-se limitar os gastos por aluno nas Universidades Públicas cobrando tarifas escolares e expandindo os programas como o PROUNI e o FIES em Universidades Públicas (p. 138) (MOREIRA, 2018, p. 210).

Diante das recomendações apresentadas pelo Banco, verifica-se a tendência de responsabilizar o sistema educacional como um "problema" que contribui para o agravamento da crise capitalista, alegando que os recursos destinados a esse setor são mal gastos. Afirma que privatização no nível médio e superior pode contribuir para o aliviamento da crise, porém Amaral (2017), ao analisar as implicações desse documento, evidencia equívocos conceituais e dados flagrantes do documento em questão. $O$ autor ressalta que é necessário ponderar os demais fatores que compõem essa conjuntura, uma vez que o documento exibe um conjunto de ações que devem ser acatadas pelo governo, para reduzir os gastos com serviços públicos, ou seja, uma iniciativa à privatização, um agravamento na desvalorização de professores e do sistema educacional público (AMARAL, 2017).

Com relação aos documentos produzidos pelo BM, salienta-se que, em alguns casos, são encomendados pelo próprio governo. Krawczyk (2002) pondera que ao pesquisar sobre esses textos e as políticas contidas deve-se considerar que: "[...] quase todas as publicações pesquisadas são feitas a partir de informações oficiais oferecidas pelos governos nacionais ou locais, de papers encomendados a profissionais envolvidos nas reformas e de documentos de outros organismos internacionais" (KRAWCZYK, 2002, p. 44).

Indícios de uma educação dentro dos moldes do Banco exemplificam-se por meio das avaliações externas. Com base em Castro (2009), os sistemas de avaliação construídos passaram a orientar as políticas educacionais em todos os níveis de ensino. Os resultados dessas avaliações determinam o que será realizado em sala de aula ou na formação de professores para que atinjam os padrões de qualidade estipulados por documentos do Banco Mundial e, assim, concretizam o agravamento da desvalorização dos professores no sistema educacional público, por meio de critérios meritocráticos.

No dia 29 de agosto de 2018, o BM lançou o documento específico para o contexto das eleições presidenciais de 2018, intitulado Por um ajuste justo com crescimento compartilhado: uma agenda de reformas para o Brasil (AJCC) (BANCO MUNDIAL, 2018). Pela primeira vez na história do País, o Banco propõe orientações para os candidatos à Presidência e suas equipes econômicas a desenvolver propostas. Denomina o documento como um "pacote de Notas de Políticas Públicas". Na visão do BM, as propostas devem estar concernentes e serem delineadas pela realidade avaliada e investigada pela equipe que prescreveu as análises.

As recomendações presentes destacam que o foco das propostas políticas deve se assentar na mudança da governança pública, na promoção de um "Estado mais eficiente" (BANCO MUNDIAL, 2018, p. 3), frente ao cenário que o País apresenta e que foi decorrente 
Banco Mundial e as Recomendações Atuais para as Políticas Educacionais no Brasil

do próprio fracasso do Estado. O documento apresenta três desafios principais, para o Brasil, diante dos sintomas do fracasso do Estado e que exigirão mudanças fundamentais de governança pública: a) a efetivação do equilíbrio fiscal; b) um crescimento sustentado da produtividade; c) serviços básicos públicos eficientes e que gerem resultados. No que tange às regras fiscais e ajuste equilibrado dos gastos, o Banco propõe flexibilização das leis, menos rigidez, como ressalta:

[...] introdução de medidas de correção automática mais rigorosas se o teto de gastos for ultrapassado. $O$ teto já inclui tais medidas, notadamente: (i) congelamento dos salários nominais do serviço público; e (ii) aumento do salário mínimo apenas pela inflação. Estimamos que essas medidas resultariam em economia de cerca de $0,3 \%$ do PIB anualmente, ou metade do ajuste implícito no teto. Seriam necessárias medidas adicionais de ajuste automático para estabilizar os níveis de endividamento até 2026 com foco na previdência e na folha de pagamento, os principais impulsionadores dos gastos atuais (BANCO MUNDIAL, 2018, p. 15).

A retórica da governança está presente na lógica dos empréstimos e suas condicionalidades. Em crítica recente sobre a atuação do BM e suas recomendações para o ajuste das políticas sociais na América Latina, Pereira (2018) evidencia que a recomendação de "[...] boa governança estava atrelada à promoção de democracias de mercado". Empurrada pelo governo americano, tal categoria logo converteu-se em condição de reconhecimento e parâmetro de avaliação da qualidade do regime político e da engenharia institucional dos países pobres e em desenvolvimento (PEREIRA, 2018, p. 2193).

O BM alega que "o salário mínimo aumentou muito mais rápido do que a produtividade do trabalho" (p. 19) e que atualmente não existe mais a lógica para o aumento de salários. Nas análises do banco, "[...] a recessão de 2015-16 foi associada a um grande aumento do desemprego, enquanto os salários reais caíram apenas moderadamente" (BANCO MUNDIAL, 2018, p. 19). Nesse sentido, enfatiza que:

A política de valorização dos salários, portanto, funcionou nas circunstâncias específicas da 'década de ouro'. No entanto, a situação mudou a partir de 2013, se não antes. Os preços das commodities caíram de seus picos históricos, o crédito se contraiu, a taxa de câmbio real sofreu depreciação, e a tentativa do governo de lutar contra essas forças por meio de políticas fiscais expansionistas não teve sucesso, resultando em quebra da confiança na estabilidade macroeconômica e agravamento das condições financeiras (BANCO MUNDIAL, 2018, p. 20).

Para a aplicabilidade das recomendações, o BM sugere que o Brasil desenvolva um compromisso com maior integração internacional e concorrência estrangeira como sendo uma espécie de âncora para um programa de políticas que aumente a concorrência em sua economia e, por meio disso, a competitividade de seu setor empresarial. O Banco enfatiza que esse alcance se efetiva por via da melhora na capacitação do capital humano para a garantia dos benefícios do crescimento econômico no País, pois na visão da agência: "[...] Trabalhadores melhor instruídos também estarão mais bem equipados para se beneficiar e se adaptar às mudanças nas oportunidades econômicas resultantes da abertura da economia e do aumento da concorrência" (BANCO MUNDIAL, 2018, p. 32).

Com relação ao financiamento para o alcance da qualidade da educação, o BM preconiza que não é possível melhorar a qualidade da educação simplesmente gastando mais 
Banco Mundial e as Recomendações Atuais para as Políticas Educacionais no Brasil

dinheiro, pois novamente volta a afirmar que o Brasil gasta 6,6\% do PIB em educação, mais que a média dos países da OCDE e países de renda média (BANCO MUNDIAL, 2018, p. 33).

Entretanto, as afirmações do Banco, quanto ao investimento não consideram o cumprimento da meta 20 da Lei $n^{\circ} 13.005 / 2014$, que compreende:

[...] Ampliar o investimento público em educação pública de forma a atingir, no mínimo, o patamar de 7\% (sete por cento) do Produto Interno Bruto - PIB do País no 5o (quinto) ano de vigência desta Lei e, no mínimo, o equivalente a $10 \%$ (dez por cento) do PIB ao final do decênio (BRASIL, 2015, p. 335).

A defesa da diminuição dos gastos em educação não respeita as estratégias elaboradas no Plano Nacional de Educacional, que prevê o aumento do investimento na educação com o objetivo de garantir uma educação em todos os níveis, etapas e modalidades e a superação das desigualdades regionais.

Diante das recomendações que priorizam o ajuste das contas públicas, o BM coloca em evidência a necessidade de repensar a governança pública mediante uma reforma do Estado em vários níveis e expõe que "para fazê-lo, o Brasil não precisará partir do zero" (BANCO MUNDIAL, 2018, p. 37). Nota-se que os documentos do BM analisados nesta pesquisa dialogam entre si e apresentam recomendações rumo à privatização dos serviços públicos, compatíveis com o mercado de trabalho internacional.

\section{Considerações Finais}

A análise dos documentos do BM selecionados identificou uma consonância de ações governamentais com recomendações que retomam, de forma intensa, as políticas de ajustes estruturais neoliberais, com vistas a instituir o lucro e a minimizar os investimentos na área social, por meio de menor intervenção do Estado nos serviços públicos.

Com essa investigação foi possível evidenciar que a influência das recomendações do BM acaba por refletir na reorganização das prioridades da educação brasileira, de maneira que passam a existir atores que defendem as recomendações do Banco. As categorias políticas propaladas pelo BM passam a compor uma teia de ideias a serem disputadas no terreno de constatação e enfrentamentos no campo da formulação da agenda política para a educação. São propostas que visam a atender demandas do mercado, por meio das ações da Nova Gestão Pública (NGP), mediante governança corporativa, a aplicabilidade da EC $n^{\circ}$ 95/2016 (BRASIL, 2016) e outras flexibilizações de leis que visam ao contingenciamento e cortes de recursos no setor público, os quais impedirão a efetivação dos direitos sociais. No que tange à sonegação, isenção e renúncias fiscais, ao aumento de impostos para os mais ricos, as recomendações inexistem nos documentos analisados.

Assim, as recomendações formuladas pelo Banco e que direcionam para a aplicabilidade da EC n 95/2016 (BRASIL, 2016) pautam-se na privatização da escola pública, enxugamento do quadro de professores, na política de meritocracia e consideram que as soluções para as mazelas da má qualidade no campo educacional estão assentadas no conceito do mercado com autonomia, eficácia, desempenho, competência e avaliação. Ao identificar as categorias políticas presentes nos quatro documentos, podem-se destacar as seguintes no primeiro documento, EPP (BANCO MUNDIAL, 2011): Eficiência, Focalização na pobreza, Focalização do investimento no setor privado, Política de desempenho/meritocracia, Avaliação e Focalização no crescimento econômico. No segundo documento, RCICS 
Banco Mundial e as Recomendações Atuais para as Políticas Educacionais no Brasil

(BANCO MUNDIAL, 2016), foram evidenciadas as categorias de Diminuição dos gastos públicos, Reforma da previdência, Diminuição dos gastos com pesquisa e Focalização na pobreza.

Com a análise do terceiro documento, AJ (BANCO MUNDIAL, 2017), foram identificadas recomendações centradas nas seguintes categorias: Privatização dos serviços públicos, Redução salarial, Reforma da previdência, Terceirização de serviços, Avaliação do desempenho, Privatização do ensino superior. Por fim, no quarto documento, AJCC (BANCO MUNDIAL, 2018), as categorias Flexibilização das leis, Congelamento/redução dos salários, Governança corporativa do Estado e Reforma do Estado foram as principais recorrentes.

Uma tendência que se percebeu, desde a década de 1990, é que as políticas brasileiras em resposta às recomendações do Banco passaram a priorizar a educação básica com medidas pautadas na focalização da pobreza e equidade, bem como a lançar o ensino médio e superior aos mecanismos de privatização e terceirização de funções. Todavia, no atual contexto, o ápice das medidas neoliberais, sob a influência do BM, está na aprovação da EC n 95/2016 (BRASIL, 2016) e nos seus desdobramentos, que visam a reduzir a intervenção do Estado nos serviços públicos e arruinar com as políticas sociais.

Vivencia-se um ordenamento de reformas que geram a desconstrução de políticas educacionais que foram efetivadas na década passada por meio de lutas, enfrentamentos e resistências. Entretanto, os documentos analisados não consideram o processo histórico da educação brasileira, como também não apresentam dados aprofundados e com clareza na indicação de suas fontes.

Ao término destas considerações, torna-se notável que não se podem desconsiderar as mazelas desencadeadas pelo capital rentista como as políticas austeras que agravam a crise, o desemprego e a pobreza no País. As reformas são necessárias na priorização dos serviços públicos, porém, devem se constituir com a participação democrática dos envolvidos historicamente no processo, em especial, com a comunidade escolar, com os profissionais, pesquisadores da educação, associações e entidades representativas da área, para a garantia de uma ampliação do financiamento público às escolas públicas.

\section{Referências}

ALTMANN, H. Influências do Banco Mundial no projeto educacional brasileiro. Educação e Pesquisa, São Paulo, v. 28, n. 1, jan./jun. 2002.

AMARAL, N. C. Uma análise do documento "Um Ajuste Justo: análise da eficiência e equidade do gasto público no Brasil”. Goiás: UFG, 2017.

AVRITZER, L. O pêndulo da democracia no Brasil: uma análise da crise 2013-2018. Revista Novos Estudos, CEBRAP, São Paulo, v. 37, n. 02, p. 273-289 maio/ago. 2018. Disponível em <http://www.scielo.br/pdf/nec/v37n2/1980-5403-nec-37-02-273.pdf>. Acesso em: 25 maio 2019.

BALL, S. J. Entrevista com Stephen J. Ball: um diálogo sobre justiça Social, pesquisa e política educacional. In: MAINARDES, J.; MARCONDES, M. I. Educação e Sociedade, Campinas, v. 30, n. 106, p. 303-318, jan./abr. 2009. 
Banco Mundial e as Recomendações Atuais para as Políticas Educacionais no Brasil

BANCO MUNDIAL. Prioridades y estrategias para la educacion: Examen Del Banco Mundial. Washington, 1995.

BANCO MUNDIAL. Guia prático da governança corporativa: experiências do círculo de companhias da América Latina. 2009.

BANCO MUNDIAL. Banco internacional para a reconstrução e o desenvolvimento e corporação financeira internacional: estratégia de parceria de país para a república federativa do Brasil exercícios fiscais (2012 a 2015). 2011.

BANCO MUNDIAL. Retomando o caminho para a inclusão, o crescimento e a sustentabilidade. 2016.

BANCO MUNDIAL. Um Ajuste Justo: Análise da eficiência e equidade do gasto público no Brasil. Washington, 2017.

BANCO MUNDIAL. Por um ajuste justo com crescimento compartilhado: uma agenda de reformas para o Brasil, 2018.

BANCO MUNDIAL. Office of executive diretor - EDS21. 2019.

BORGES, André. Governança e política educacional: a agenda recente do Banco Mundial. Revista Brasileira de Ciências Sociais, v. 18, n. 52, 2003.

BRASIL DEBATE. FUNDAÇÃO FRIEDRICH EBERT. Austeridade e retrocesso: impactos sociais da política fiscal no Brasil. São Paulo. 2018. Disponível em: <http://library.fes.de/pdffiles/bueros/brasilien/14632.pdf>. Acesso em: 25 maio 2019.

BRASIL. Plano Nacional de Educação 2014-2024: Linha de base. Brasília, DF: Inep, 2015.

BRASIL. Emenda Constitucional $\mathrm{n}^{\circ}$ 95, de 15 de setembro de 2016. Altera o Ato das Disposições Constitucionais Transitórias, para instituir o Novo Regime Fiscal, e dá outras providências. Diário Oficial da União, Brasília, Senado Federal, 2016.

CARDOZO, M. J. P. B. Crise do capital: ajuste estrutural e as reformas educacionais propostas pelo Banco Mundial, 2005.

CASIMIRO, F. H. A nova direita no Brasil. São Paulo: Expressão Popular, 2018.

CASTRO, M. H. G. Sistemas de Avaliação da Educação no Brasil: avanços e novos desafios. Perspectivas, São Paulo, n. 1, v. 23, 2009.

DE BONIS, D. Políticas de remuneração variável na educação pública brasileira: uma análise comparada. Revista Temas de Administração Pública, Araraquara, v. 10, n. 1, p.67-86, 2015.

FONSECA, M. O financiamento do Banco Mundial à educação brasileira: vinte anos de cooperação internacional. In: DE TOMMASI, L.; WARDE M. J.; HADDAD, S. O Banco Mundial e as políticas educacionais. 2. ed. São Paulo: Cortez, 2003. p. 229-251.

FREITAS, L. C. A reforma empresarial da educação: nova direita, velhas ideias. São Paulo: Expressão Popular, 2018. 
Banco Mundial e as Recomendações Atuais para as Políticas Educacionais no Brasil

FUNDAÇÃO ULYSSES GUIMARÃES; PMDB. Uma ponte para o futuro. 2016. Disponível em: <http://www.fundacaoulysses.org.br/wp-content/uploads/2016/11/UMA-PONTE-PARAO-FUTURO.pdf>. Acesso em: 02 abr. 2019.

GAJARDO, M. Reformas educativas en América Latina balance de una década. In: PREAL, 15., 1999, Santiago. Documento de Trabajo. Santiago de Chile, set. 1999.

JINKINGS, I.; DORIA, K.; CLETO, M. Por que gritamos golpe? Para entender o impeachment e a crise política no Brasil. São Paulo: Boitempo, 2016. p. 61-67.

KRAWCZYK, N. A sustentabilidade da reforma educacional em questão: aposição dos organismos internacionais. Revista Brasileira de Educação, Rio de Janeiro, n. 19, p. 43-62, 2002.

LEHER, R. Da ideologia do desenvolvimento à ideologia da globalização: a educação como estratégia do Banco Mundial para alívio da pobreza. 1998. Tese (Doutorado em Educação) - Universidade de São Paulo, São Paulo, 1998.

LEHER, R. Um Novo Senhor da Educação? A política educacional do Banco Mundial para a periferia do capitalismo. Outubro, São Paulo, v. 1, n. 3, p. 19-30, 1999.

LUCENA, C.; PREVITALI, F. S.; LUCENA, L. A crise da democracia brasileira. Uberlândia: Editora Navegando, 2017.

MOREIRA, J. A. S. Políticas Públicas para a educação infantil no Brasil (1990-2001). Maringá: EDUEM, 2012.

MOREIRA, J. A. S. Políticas de Financiamento e Gestão da Educação Básica (19902010): os casos Brasil e Portugal. Maringá: EDUEM, 2015.

MOREIRA, J. A. S. Reformas educacionais e políticas curriculares para a educação Básica: prenúncios e evidências para uma resistência ativa. Revista Germinal, v. 10, n. 02, p. 199213, 2018.

NASCENTES, Ana Luisa; SALINET, Maria Fernanda. O labirinto das verbas para a educação. Zero. Jornal-laboratório do curso de Jornalismo da UFSC, Florianópolis, 2017. Disponível em: <https://medium.com/@zeroufsc/o-labirinto-das-verbas-para-a-educa\%C3\%A7\%C3\%A3o47648d8ce3da>. Acesso em: 25 maio 2019.

PANSARDI, M. V. A Formação de Professores e o Banco Mundial. Caderno do Simpósio Brasileiro de Política e Administração da Educação, Porto Alegre, ANPAE, 2009.

PEREIRA, J. M. M. O Banco Mundial como ator político, intelectual e financeiro (19442008). Rio de Janeiro: Civilização Brasileira, 2010.

PEREIRA, J. M. M. Banco Mundial, reforma dos Estados e ajuste das políticas sociais na América Latina. Ciência \& Saúde coletiva, Rio de Janeiro, v. 23, n. 7, p. 2187-2196, 2018.

PRONKO, M. A. O Banco Mundial no campo internacional da educação. In: PRONKO, M. A.; PEREIRA, J. M. M. (Org.). A demolição de direitos: um exame das políticas do Banco Mundial para a educação e a saúde (1980-2013). Rio de Janeiro: EPSJV, 2014. v. 1. p. 89112. 
Banco Mundial e as Recomendações Atuais para as Políticas Educacionais no Brasil

ROSSI, P.; DWECK, E. Impactos do novo regime fiscal na saúde e educação. Espaço temático: austeridade fiscal, direitos e saúde. Caderno Saúde Pública, v. 32, n. 12, 2016. Disponível em: <https://www.scielosp.org/scielo.php?pid=S0102311X201600140050 1\&script=sci_arttext $>$. Acesso em: 25 maio 2019.

RUIZ, M. J. F.; BUFALO, K. S. Uma ponte para o futuro: políticas educacionais e parcerias público-privadas. Educação em Análise, Londrina, v. 2, n. 1, p. 37-58, jan./jun. 2017. Disponível em: <http://www.uel.br/revistas/uel/index.php/educanalise/article/view/29921>. Acesso em: 25 maio 2019.

SANTOS, L. L. de C.P. A implementação de políticas do Banco Mundial para a formação docente. Cadernos de Pesquisa, Belo Horizonte, UFMG, n. 11, p. 173-182, dez. 2000.

SILVA, M. A. Do projeto político do banco mundial ao projeto político-pedagógico da escola pública brasileira. Cadernos Cedes, Campinas, v. 23, n. 61, p. 283-301, dez. 2003.

SILVA, M. A. O consenso de Washington e a privatização da educação brasileira. Revista Linhas Críticas, v. 11, n. 21, p. 255-264, jul./dez. 2005.

SOARES, M. C. C. Banco Mundial: políticas e reformas. In: TOMMASI, L.; WARDE, M. J.; HADDAD, S. (Org.). O Banco Mundial e as Políticas Educacionais. 6. ed. São Paulo: Cortez, 2009. p. 15-39.

TOMMASI, L.; WARDE, M. J.; HADDAD, S. (Org.). O Banco Mundial e as Políticas Educacionais. São Paulo: Cortez, 2003.

UNESCO. Clasificación Internacional Normalizada de la Educación (CINE). 2011. Disponível em: <https://unesdoc.unesco.org/ark:/48223/pf0000220782>. Acesso em: 28 maio 2019.

Jani Alves da Silva Moreira é doutora em Educação (UEM). Docente Adjunto do Programa de Pós-graduação em Educação (PPE) e do Departamento de Teoria e Prática da Educação da Universidade Estadual de Maringá (UEM). Líder do Grupo de estudos e pesquisas em políticas educacionais, gestão e financiamento da educação (GEPEFI/CNPq).

ORCID: http://orcid.org/0000-0002-3008-0887

E-mail: professorajani@hotmail.com

Telma Adriana Pacifico Martineli é Doutora em Educação (UEM). Docente Adjunto do do Programa de Pós-graduação em Educação (PPE) e doDepartamento de Educação Física (DFE) da Universidade Estadual de Maringá (UEM). Líder do Grupo de Estudos e Pesquisas em Educação, Políticas e Práticas Pedagógicas da Cultura Corporal.

ORCID: http://orcid.org/0000-0003-2997-2957

E-mail: telmamartineli@hotmail.com

Renata Valério da Silva é Mestranda em Educação (PPE/UEM). Graduada em Pedagogia (UEM). Bolsista CAPES. Estudante do Grupo de estudos e pesquisas em políticas educacionais, gestão e financiamento da educação (GEPEFI/CNPq).

ORCID: http://orcid.org/0000-0003-4145-9646

E-mail: rehvalerio@gmail.com 
Banco Mundial e as Recomendações Atuais para as Políticas Educacionais no Brasil

Carolina de Moura Vasconcelos é Mestranda em Educação (PPE/UEM). Graduada em Educação Física (UEM). Bolsista CAPES. Estudante do Grupo de Estudos e Pesquisas em Educação, Políticas e Práticas Pedagógicas da Cultura Corporal.

ORCID: http://orcid.org/0000-0002-6332-1608

E-mail: carolvasconcelos.uem@gmail.com

Recebido em 28 de fevereiro de 2019 Aprovado em 08 de junho de 2019 


\section{Editores do volume 10}

Márcia Aparecida Jacomini - Universidade Federal de São Paulo, Brasil

José Marcelino de Rezende Pinto - Universidade de São Paulo, Brasil

\section{Comitê Editorial}

Nalú Farenzena - Universidade Federal do Rio Grande do Sul, Brasil

Juca Gil - Universidade Federal do Rio Grande do Sul, Brasil

Theresa Adrião - Universidade Estadual de Campinas, Brasil

Ângelo Ricardo de Souza - Universidade Federal do Paraná, Brasil

\section{Conselho Editorial}

\section{Alejandro Morduchowicz}

Universidad Pedagógica, Provincia de Buenos Aires, Argentina

Andréa Barbosa Gouveia

Universidade Federal do Paraná, Brasil

Fernanda Saforcada

Universidade de Buenos Aires, Argentina

Jacques Velloso

Universidade de Brasília, Brasil

João Monlevade

Senado Federal, Brasil

Jorge Abrahão de Castro

Instituto de Pesquisa Econômica Aplicada / IPEA, Brasil

Lisete Regina Gomes Arelaro

Universidade de São Paulo, Brasil

Luis Carlos Sales

Universidade Federal do Piauí, Brasil

Luiz de Sousa Junior

Universidade Federal da Paraíba, Brasil

Luiz Fernandes Dourado

Universidade Federal de Goiás, Brasil

Magna França

Universidade Federal do Rio Grande do Norte, Brasil

Marcos Edgar Bassi

Universidade Federal de Santa Catarina, Brasil

Maria Angélica Pedra Minhoto

Universidade Federal de São Paulo, Brasil

Maria Beatriz Luce

Universidade Federal do Rio Grande do Sul, Brasil

Maria Dilnéia Espíndola Fernandes

Universidade Federal de Mato Grosso do Sul, Brasil

Nelson Cardoso do Amaral

Universidade Federal de Goiás, Brasil

Nicholas Davies

Universidade Federal Fluminense, Brasil

Robert E. Verhine

Universidade Federal da Bahia, Brasil

Romualdo Portela de Oliveira

Universidade de São Paulo, Brasil

Rosana Gemaque Rolim

Universidade Federal do Pará, Brasil

Rubens Barbosa de Camargo

Universidade de São Paulo, Brasil

Theresa Adrião

Universidade Estadual de Campinas, Brasil

Tristan McCowan

University of London, Reino Unido

Vera Jacob

Universidade Federal do Pará, Brasil

Vera Peroni

Universidade Federal do Rio Grande do Sul, Brasil

Vitor Henrique Paro

Universidade de São Paulo, Brasil

\section{Equipe editorial}

Apoio ao Comitê Editorial: Caio Cabral da Silva

Diagramação, Revisão de português e normalização: Edson Leonel de Oliveira

Revisão de inglês: Sabrina Ferreira

Fineduca - Revista de Financiamento da Educação

Associação Nacional de Pesquisa em

Financiamento da Educação

e-mail: revista.fineduca@gmail.com | site: http://seer.ufrgs.br/fineduca 